\title{
An Overview about Using the 3D Printing Technology
}

\author{
Hasan Nazha* and Szávai Szabolcs \\ Faculty of Mechanical Engineering and Informatics, University of Miskolc, Miskolc, Hungary. *Corresponding Author's Email: \\ hasan.nazha@uni-miskolc.hu
}

\begin{abstract}
3D printers are distinct from other manufacturing technologies in that they provide faster, easier, and less costly solutions, in addition, allowing the design of different complex configurations that need to overlap many normal manufacturing processes. Because of the significance of this technology, several countries have seen the benefit of spreading awareness of its significance in addition to training students on the way of using it. 3D printing continues to amaze us with its capabilities and uses, and we hope to see it available in all schools and universities well so that students can have the space for creativity and innovation.
\end{abstract}

Key words: 3D printing; Additive manufacturing; Overview.

\section{Introduction}

The beginning of the emergence of 3D printing more than 10 years ago, contrary to what some think, however, the interest in it has begun to grow in recent years in a unique manner, in addition, the 3D printers were expensive at first, and could not be obtained easily (1). However, today, with the removal of many obstacles such as the high price, it has become possible to obtain different shapes and characteristics of 3D printers, which can be available at different prices. It has become possible to obtain a $3 \mathrm{D}$ printer at a price of less than $\$ 500$ after its prices were more than 50 thousand dollars (2).

3D printers are distinct from other manufacturing technologies in that they provide faster, easier, and less costly solutions, in addition, allowing the design of different complex configurations that need to overlap many normal manufacturing processes (3). At first, plastic was the only material used in 3D printing, however, with the technological development recently, various materials were introduced such as ceramics, silver, gold, titanium and gypsum (4).

3D printing has entered life in a way more than you can imagine, it has become used in space sciences, engineering, medicine, science and entertainment, and with this type of printer it will be easier to get a lot of materials and tools at lower prices, in the field of medicine. For example, it has become possible to design many models of tissues. Moreover, organs such as the liver, kidney, heart are all easy to manufacture, and it is currently possible to manufacture orthotics and prosthetics, and other medical devices (5). Surgeons from China have already succeeded in implanting the skull (manufactured in the 3D printing technique) of a girl with hydrocephalus, and in a normal way, the skull

This is an Open Access article distributed under the terms of the Creative Commons Attribution CC BY license (http://creativecommons.org/licenses/by/4.0/), which permits unrestricted reuse, distribution, and reproduction in any medium, provided the original work is properly cited.

(Received 25 November 2021; Revised 08 December 2021; Accepted 20 December 2021) 
continues to grow (6).

With this type of printer, a lot of imagination has become a reality, as it is possible to manufacture what you imagine of shoes, furniture, models and toys with ease, and it is now possible to design the wanted map and then build a dream house in the wanted dimensions using 3D printing (7). A company in China has succeeded in building ten fullsize houses using a 3D printer, and it took only one day to print (construct) the buildings using fastdrying cement (8).

In the field of space science, NASA (the US space agency) sent a 3D printer with astronauts to the International Space Station, and they were able to print one of the station's components using it, in an important step for self-sufficiency in the manufacture of damaged spare parts (9). Many scientists who are interested in this technology highly believe that it will significantly contribute to reducing a lot of money, effort, and time, as one company, as an example, has manufactured an entire car ready to drive utilizing this technology within only forty hours, with the projections that this period will be reduced to only twenty-four hours. This technology is also considered environmentally friendly, as it is expected to use non-recyclable plastics, cement residues and mine waste in the manufacture of useful materials and tools (10).

Because this technology is significant, many countries have seen that it is important to spread awareness of its significance and training students on how to use it. In the United States, many summer camps are held for students to teach them how to use 3D printers. In Tokyo (Japan), they have made 3D printing courses for small schools, and Singapore has shown a readiness to provide every primary school with a 3D printer. It is worth to be mentioned that it could be integrated with CAD technique, which in turn use in education and many other fields (11-23).

\section{The most important advantages of 3D printers' usage}

With the presence of these 3D printers in schools and universities, everything will be within reach. The students can print 3D models of mountains, terrain, flats, etc. in their Geography subject. In addition, they are able to feel and see the organs more accurately in a science subject, and in History, they can design or print several ancient buildings like pyramids and others, and the engineering student has ample field to make his engineering designs a reality, and the list goes on about this field (24).

Another advantage of the presence of 3D printers is encouraging innovation and creativity, which will help create more opportunities for innovation and creativity, and find solutions to many problems on the national and international levels while providing opportunities, resources, support and tools (25).

The use of 3D printing technology could help achieve the goals of the Science, Technology, Engineering, Art and Math (STEAM) approach (26). In addition, finding solutions to global problems, although scientists and engineers are busy finding solutions to many global problems, providing opportunities for students to participate in solving global problems has become an exciting thing. Students at St Stephen's School (Australia), for example, were able to employ 3D printing to find a solution to a medical problem in their community (27).

\section{Challenges in the widespread use of 3D printing}

Despite the advantages of 3D printing and its unique features, there are many concerns about printing some illegal or dangerous materials and tools such as weapons (28).

\section{Conclusion}

3D printing technology continues to astonish us with its uses and capabilities, and we hope to see it available in many many fields and use it well so that the users can have the space for creativity and innovation.

\section{Conflict of Interest}

The authors declare that there is no conflict of interests regarding the study or this article. 


\section{References}

1. Tofail SA, Koumoulos EP, Bandyopadhyay A, Bose S, O’Donoghue L, Charitidis C. Additive manufacturing: scientific and technological challenges, market uptake and opportunities. Materials today. 2018 Jan 1;21(1):22-37.

2. Ngo TD, Kashani A, Imbalzano G, Nguyen KT, Hui D. Additive manufacturing (3D printing): A review of materials, methods, applications and challenges. Composites Part B: Engineering. 2018 Jun 15;143:172-96.

3. Parupelli S, Desai S. A comprehensive review of additive manufacturing (3d printing): processes, applications and future potential. American journal of applied sciences. 2019 Sep;16(8).

4. Das AK, Agar DA, Rudolfsson M, Larsson SH. A review on wood powders in 3D printing: Processes, properties and potential applications. Journal of Materials Research and Technology. 2021 Aug 10.

5. Shahrubudin N, Koshy P, Alipal J, Kadir MH, Lee TC. Challenges of 3D printing technology for manufacturing biomedical products: A case study of Malaysian manufacturing firms. Heliyon. $2020 \mathrm{Apr}$ 1;6(4):e03734.

6. https://www.ndtv.com/world-news/3d-printed-skullimplanted-in-3-year-old-chinese-girl-782516

7. Mertz L. Dream it, design it, print it in 3-D: What can 3-D printing do for you?. IEEE pulse. 2013 Nov 6;4(6):15-21.

8. https://www.bbc.com/news/blogs-news-fromelsewhere-27156775

9. https://www.nasa.gov/content/open-for-business-3d-printer-creates-first-object-in-space-oninternational-space-station/

10. OECD (2017), The Next Production Revolution: Implications for Governments and Business, OECD Publishing, https://doi.org/10.1787/9789264271036-en.

11. Darwich A, Nazha H, Daoud M. Effect of Coating Materials on the Fatigue Behavior of Hip Implants: A Three-dimensional Finite Element Analysis. Journal of Applied and Computational Mechanics. 2020 Apr 1;6(2):284-95.

12. Shash M, Nazha H, Abbas W. Influence of different abutment designs on the biomechanical behavior of one-piece zirconia dental implants and their surrounding bone: A 3D-FEA. Irbm. 2019 Dec 1;40(6):313-9.

13. Darwich A, Nazha H, Abbas W. Numerical study of stress shielding evaluation of hip implant stems coated with composite (carbon/PEEK) and polymeric (PEEK) coating materials. Biomedical Research. 2019;30(1):169-74.

14. Darwich A, Nazha H, Sliman A, Abbas W. Ankle-foot orthosis design between the tradition and the computerized perspectives. The International journal of artificial organs. 2020 May;43(5):354-61.

15. Morshed W, Abbas L, Nazha H. Heating performance of the PVC earthair tubular heat exchanger applied to a greenhouse in the coastal area of west Syria: An experimental study. Thermal Science and Engineering Progress. 2021 Jun 21:101000.

16. Darwich A, Shash M, Ali A, Nazha H, Marouf A, Abbas W. Numerical study of the influence of ultra-thin veneer materials and its thickness on their biomechanical behavior. Biomedical Research. 2019;30(6):920-3.

17. Khalil E, Youssef H, Nazha H. A Numerical Study of the Induced Stresses in the Separation Points of the Tensile Element (Chain) of the Plate Conveyor Used in the Blowing Unit in Water Factories. Journal of Engineering Research and Reports. 2019 Jul 11:1-9.

18. Darwich A, Nazha H, Nazha A, Daoud M, Alhussein A. Bio-Numerical Analysis of the Human Ankle-Foot Model Corresponding to Neutral Standing Condition. Journal of Biomedical Physics \& Engineering. 2020 Oct;10(5):645.

19. Nazha H. Investigating the potential use of polymeric materials in the preparation of temporary cosmetic teeth painting veneers. Materials Research Express. 2020 Jul 29;7(7):075307.

20. Darwich A, Alammar A, Heshmeh O, Szabolcs S, Nazha $H$. Fatigue loading effect in custom-made all-on-4 implants system: A 3D finite elements analysis. IRBM. 2021 Jun 21.

21. Darwich A, Aljareh A, Aladel O, Szávai S, Nazha H. Biomechanical Assessment of the Influence of Inlay/Onlay Design and Material on Stress Distribution in Nonvital Molars. European Journal of General Dentistry. 2021 Oct 18.

22. Nazha H, Nazha ZA. A Comparative Study Between Epoxy S-Glass UD And Epoxy Carbon UD For Their Use As Manufacturing Materials For Wind Turbine Blades.

23. Darwich A, Attieh A, Khalil A, Szávai S, Nazha H. Biomechanical assessment of orbital fractures using patient-specific models and clinical matching. Journal of Stomatology, Oral and Maxillofacial Surgery. 2021 Sep 1;122(4):e51-7.

24. Szulżyk-Cieplak J, Duda A, Sidor B. 3D printers-new possibilities in education. Advances in Science and Technology Research Journal 2014;8(24):96-101.

25. Eslahi A, Chadeesingh DR, Foreman C, Alpay E. 3D printers in engineering education. Enhancing StudentCentred Teaching in Higher Education. 2020:97-112.

26. Lee SG, Lee JY, Park KE, Lee JH, Ahn SC. Mathematics, art and 3D-printing in STEAM education. Communications of Mathematical Education. 2015;29(1):35-49.

27. https://www.makersempire.com/st-stephensproject-based-learning/

28. Fey M. 3D Printing and International Security. Peace Research Institute Frankfurt, PRIF Report. 2017(144). 